Research, Society and Development, v. 9, n. 11, e3499119817, 2020

(CC BY 4.0) | ISSN 2525-3409 | DOI: http://dx.doi.org/10.33448/rsd-v9i11.9817

\title{
Análise de encosta em situação de risco no município de Olinda-PE
}

Risk analysis of hillside in Olinda-PE

\section{Análisis de talud en riesgo en el municipio de Olinda-PE}

Recebido: 31/10/2020 | Revisado: 06/11/2020 | Aceito: 12/11/2020 | Publicado: 17/11/2020

\author{
Aléssia de Albuquerque Pedrosa \\ ORCID: https://orcid.org/0000-0002-4625-5725 \\ Universidade de Pernambuco, Brasil \\ E-mail: aap_pec@poli.br \\ Suyanne Monteiro de Almeida \\ ORCID: https://orcid.org/0000-0002-0359-0152 \\ Universidade de Pernambuco, Brasil \\ E-mail: sma_pec@poli.br \\ Kalinny Patrícia Vaz Lafayette \\ ORCID: https://orcid.org/0000-0002-7954-2317 \\ Universidade de Pernambuco, Brasil \\ E-mail: klafayette@poli.br
}

\section{Resumo}

A retirada da vegetação original, a deposição irregular de lixo e resíduo, o aumento da área impermeável em locais de encostas, atrelado aos altos índices pluviométricos, acabam por desencadear acidentes que geram danos materiais e à própria vida dos moradores. Dessa forma, o presente trabalho tem o objetivo de avaliar o grau de risco de uma encosta localizada no município de Olinda-PE. A metodologia consistiu em visita ao local para avaliação dos fatores que potencializam os deslizamentos, seguido de uma análise quantitativa da dinâmica de ocupação do local através do software Qgis entre os anos de 1975 e 2018. Por fim, foi realizado a análise qualitativa através da matriz de probabilidade/consequência para avaliação do risco no local. Com o passar do tempo, o percentual de área referente a mancha urbana aumentou $122,95 \%$ e o percentual de vegetação, reduziu 55,40\%. Foi avaliado que, para a área de estudo, os impactos ambientais analisados afetam ou interferem em nível mediano. As ações antrópicas com maior probabilidade de gerar impactos na área foram o uso e a ocupação do solo, o esgoto lançado diretamente no solo e a supressão da cobertura vegetal. 
Palavras-chave: Deslizamentos; Solo; Análise temporal.

\begin{abstract}
Removing original vegetation, irregularly waste dispositioning, increasing impermeable area on slopes, along with high rainfall, cause accidents that generate property damage and risk to people. Thus, the present study aims to assess the risk degree for a slope located in Olinda, Pernambuco, Brazil. As for the methodology, there was a site visit to assess factors that enhance the landslides followed by a quantitative analysis of the occupation dynamics at the site, through Qgis software, from 1975 to 2018. Finally, a qualitative analysis was carried out through the matrix of probability/consequence for risk assessment. Over time, the percentage of urban areas increased by $122.95 \%$ while the percentage of vegetation decreased by $55.40 \%$. It was concluded that the environmental impacts affect or interfere at a median level. The anthropic actions most likely to have an impact on the area were: land use and occupation, sewage released directly into the soil, and vegetation cover suppression.
\end{abstract}

Keywords: Landslides; Soil; Temporal analysis.

\title{
Resumen
}

La remoción de la vegetación original, la deposición irregular de basura y desperdicios, el aumento de la superficie impermeable en pendientes, ligados a las altas precipitaciones, terminan desencadenando accidentes que generan daños materiales y la propia vida de los vecinos. Así, el presente estudio tiene como objetivo evaluar el grado de riesgo de un talud ubicado en el municipio de Olinda-PE. La metodología consistió en una visita al sitio para evaluar los factores que potencian los deslizamientos, seguido de un análisis cuantitativo de la dinámica de ocupación del sitio utilizando el software Qgis entre los años 1975 y 2018. Finalmente, se realizó un análisis cualitativo a través de la matriz. de probabilidad / consecuencia para la evaluación de riesgos en el sitio. Con el tiempo, el porcentaje de área referida a áreas urbanas aumentó en un $122,95 \%$ y el porcentaje de vegetación disminuyó en un $55,40 \%$. Se evaluó que, para el área de estudio, los impactos ambientales analizados afectan o interfieren a nivel mediano. Las acciones antrópicas con mayor probabilidad de tener impacto en la zona fueron el uso y ocupación del suelo, las aguas residuales vertidas directamente al suelo y la supresión de la cubierta vegetal.

Palabras clave: Deslizamientos de tierra; Suelo; Análisis temporal. 


\section{Introdução}

A urbanização representa um processo rápido de adensamento demográfico que ocorre principalmente nos centros urbanos em decorrência de diversos fatores, como industrialização, melhores oportunidades de emprego e infraestrutura mais desenvolvida (Verde et al., 2020). A urbanização é um processo complexo, associado a uma visão de desenvolvimento, inerente ao avanço ocorrido no setor industrial, que provocou transformações na estrutura de produção e da sociedade, gerando no Brasil um inchaço urbano.

O inchaço urbano é um fenômeno caracterizado pela expansão acelerada e caótica de áreas urbanas e limítrofes. A busca por melhor qualidade de vida e novas possibilidades chocou-se com um espaço desprovido de infraestrutura necessária para abarcar o significativo montante populacional advindo do campo e de locais mais afastados. Tal conjuntura desencadeou uma segregação socioespacial, com assentamento irregular dessa parcela da população em regiões impróprias para habitação.

A transformação ocorrida na sociedade se revelou expressivamente no último século, onde foi observado o drástico crescimento da população brasileira, que passou de 17 milhões para 170 milhões de habitantes. Essa mudança de quantitativo foi acompanhada também do cenário adverso do povoamento da população, que se deslocou maciçamente do campo para a cidade. Tal transição demográfica está associada, especialmente, à passagem da dinâmica econômica de base primária e exportadora para uma de base urbano-industrial (A. M. S. Santos, 2020).

A construção de elementos de infraestrutura, em virtude do processo de urbanização, ocasiona diversos distúrbios ao ambiente natural, como a redução da área de vegetal e execução de obras (Wenzel, Sousa Junior, Uliana, \& Mendes, 2020). Em conjunto com a urbanização, surge a ocupação de ambientes naturalmente mais frágeis, como encostas e fundos de vales, trazendo preocupação para a sociedade em virtude da exposição ao risco de deslizamento, potencializado pelas ações antrópicas no local (Oliveira \& Giudice, 2017).

Nos últimos anos, foi perceptível o aumento das ocorrências de desastres naturais que causam prejuízos sociais, ambientais e econômicos significativos. O deslizamento de encostas é um exemplo de desastre que apresenta como principais causas a ocupação antrópica desordenada, a retirada da cobertura vegetal, a impermeabilização do solo, além dos fatores físicos pertinentes a encosta, como o ângulo de repouso do talude, o qual é frequentemente alterado com execuções de obras sem projeto (Carvalhais, Moraes, H. F. Silva, \& Bernardes, 
2019; Mello, 2018).

Segundo Abrantes, Gomes, Rocha e Teixeira (2018) e Barboza, Bezerra Neto e Caiana (2020), as dinâmicas e os padrões de uso e ocupação do solo são de grande importância, principalmente quando entra em debate as questões ligadas as alterações climáticas, desenvolvimento sustentável e preservação ambiental. O solo representa um recurso finito e fundamental para a sustentação da humanidade, sendo a sua degradação uma das questões mais criticadas e enfrentadas pela população mundial.

Para Gerui, Yalin, Huajun, Sanmang and Jianping (2017), a urbanização afeta diretamente a ocorrência de deslizamentos de terra, atuando nos aspectos de mudança de severidade, frequência, extensão e vulnerabilidade dos desastres naturais. A evolução agressiva desse processo ocorre sobretudo em países subdesenvolvidos, trazendo um crescimento desordenado do espaço urbano que apresenta um cenário despreparado para absorver a demanda da população nos requisitos de infraestrutura básica, ou seja, o mercado imobiliário acaba se apropriando de setores melhores nas cidades e esquecendo de locais destinados à moradia popular, levando a população menos favorecida a ocupar de forma irregular locais naturalmente frágeis (Carvalhais et al., 2019; Mello, 2018).

O intenso deslocamento da população para as cidades não está devidamente amparado por políticas públicas capazes de suprir a demanda por moradias em condições habitáveis. No âmbito municipal, é observado descuido do poder público com espaço urbano e a sociedade, uma vez que no plano diretor do município, instituído pela Lei complementar n. 026/2004 e alterado pela Lei complementar n. 032/2008, não está previsto medidas efetivas e eficazes no combate ao problema de segurança infraestrutural inerente às habitações situadas em áreas de risco.

Sendo assim, o presente trabalho tem o objetivo de analisar a dinâmica de ocupação de uma encosta localizada no município de Olinda-PE através do software Qgis e avaliar o risco de deslizamento através da aplicação da matriz de probabilidade/consequência identificando os indicadores que potencializam a existência de acidentes.

\section{Urbanização}

O conceito de urbanização está ligado ao ritmo de crescimento da população urbana que passou a ser notado não somente nos grandes centros urbanos, mas também em cidades intermediárias, as quais conseguem crescer mesmo fora das áreas metropolitanas de urbanização mais concentrada (Miranda \& Gomes Júnior, 2017). A urbanização é mais 
acelerada em países desenvolvidos, mas passou a acontecer também em nações subdesenvolvidas, acarretando problemas ligados à infraestrutura e à saúde humana, revelando o despreparo de alguns países em receber essa demanda populacional. A urbanização brasileira ocorreu de forma bastante acelerada acompanhado do crescimento demográfico rápido (Pereira \& Dias, 2020; A. M. S. Santos, 2020).

A urbanização é vista como uma real oportunidade para alcançar melhores condições de vida e novas oportunidades de emprego. Assim, as cidades atraíram grandes massas populacionais, que expandiram as metrópoles para além dos seus limites originais, deslocando parcela da população para zonas periféricas, sendo áreas insalubres, impróprias para habitação e carentes de serviços públicos básicos, como saneamento, educação, energia elétrica, segurança e saúde (Barboza, Bezerra Neto, \& Caiana, 2020; Verde et al., 2020).

Para Yu, Yang and Li (2019), a densidade populacional pode ser observada como uma variável de controle que permitirá uma melhor gestão ambiental, já que as áreas com maior número de pessoas necessitam de ações governamentais mais fortes, com o objetivo de reduzir a poluição e a degradação do meio ambiente, na tentativa de garantir sua organização adequada.

O processo de urbanização nacional, no entanto, não foi acompanhado por políticas públicas adequadas que permitissem o crescimento ordenado das cidades, direcionando-as para uma expansão urbana periférica. Em decorrência desse sistema, a dinâmica econômica prevaleceu sobre a organização urbana, resultando em áreas metropolitanas nas quais problemas socioambientais emergiram, demandando investimento em ações restauradoras do cenário vigente (Matos, A. L. S. Falcão, Lopes, Santiago, \& Sampaio, 2020; A. M. S. Santos, 2020).

\section{Uso e Ocupação do Solo}

O processo de urbanização ocorrido nos últimos anos foi responsável pela redistribuição da população no território brasileiro (Carvalho, 2019). A expansão da mancha urbana resultou na ocupação desigual dos centros urbanos, o que provocou o assentamento da população em áreas consideradas de risco e impróprias para a acomodação de moradias (United Nations Human Settlements Programme, 2016). O risco, associado a essas áreas, está naturalmente ligado a geomorfologia do local e principalmente relacionado a ação antrópica, no uso e ocupação do solo (Santana \& Listo, 2018; Leite, Pinheiro, \& Pamboukian, 2019).

As ações antrópicas em áreas íngremes, como é o caso de encostas, provocam 
mudanças significativas nas características do local, que intensificam sua suscetibilidade a dinâmica natural de deslizamentos (Santana \& Listo, 2018). Dentre as diversas alterações provenientes do uso e ocupação inadequados do solo, existem fatores relevantes que afetam o processo de instabilidade dessas áreas. A retirada de vegetação do solo é uma das principais práticas que prejudicam a estabilidade dos taludes, uma vez que retira a proteção do solo e o seu reforço, fornecido pelas raízes (Leite, Pinheiro, \& Pamboukian, 2019).

Ademais, atividades como cortes e aterros, lançamento de esgoto diretamente no solo, presença de fossas sanitárias, obstrução da drenagem natural, que pode ser acentuada com a deposição irregular de resíduos, além das construções também irregulares, são fatores que acentuam a fragilidade dessas áreas, pois interferem diretamente no comportamento do solo (Mello, 2018; Oliveira \& Giudice, 2017; M. J. P. Santos, T. A. Silva, \& Lafayette, 2019).

$\mathrm{O}$ uso inadequado do solo pode acarretar sérios desequilíbrios ambientais, alguns que já estão sendo vivenciados na atualidade, sendo responsável desde a degradação e instabilidade do ecossistema até o perigo existente no assentamento habitual de áreas de risco (Wenzel et al., 2020). Dessa forma, a condição atual das cidades aponta para a fragilidade do sistema moderno, demonstrando a importância do estudo e planejamento urbano, que vise contribuir com o ordenamento adequado do território (Speth, Peres, Wollmann, Domingues, \& Ribeiro, 2020).

\section{4. Áreas de Risco}

Ao se falar de risco, é inevitável absorver essa informação sob uma conotação negativa, prevalecendo o aspecto do ruim que pode acontecer, consiste numa definição herdada para indicar prejuízo. O conceito está associado a imprevisibilidade ou probabilidade de algo acontecer, situação que pode ser agravada quando é exposta ao dano ou a inconvenientes que contribuam com o cenário (Girão, Rabelo, \& Zanella, 2018).

Ainda segundo Girão, Rabelo e Zanella (2018, p.71) "partindo da forma de como o homem se organiza e ocupa o espaço, entende-se que a situação de vulnerabilidade e a suscetibilidade estão postas nas diversas realidades”. Assim, áreas íngremes, como taludes e encostas, representam locais de extrema fragilidade e risco.

Áreas íngremes apresentam habitualmente eventos de deslizamentos e movimentos de massa, processos inerentes a dinâmica natural do espaço terrestre. Contudo, atualmente, esses fenômenos considerados naturais vêm se transformando em expressivos acidentes socioambientais, quando associam a instabilidade de uma área vulnerável com sua ocupação 
irregular (E. O. Santos, N. A. M. Falcão, \& Lima, 2020). A ação antrópica nessas regiões potencializa a fragilidade da área, uma vez que retiram a vegetação que protege o solo e realizam obras que agravam a inclinação do talude, além de aumentar a sobrecarga local, contribuindo para sua condição de risco.

Nesse contexto, áreas sob situação de risco representam localidades mais vulneráveis, com sensibilidade de sofrer consequências diretas de ações antrópicas ou naturais (Andrade, Calheiros, \& Conceição, 2018). Esse panorama é observado frequentemente em encostas no município de Olinda - PE, situação que atraiu nossa atenção para uma análise mais aprofundada no local.

\section{Metodologia}

\subsection{Caracterização da área}

A área de estudo pertence ao bairro de Sapucaia, sob as coordenadas $34^{\circ} 59^{\prime} 33^{\prime \prime}$ e $7^{\circ}$ 50'33" W, na cidade de Olinda-PE, apresentada na Figura 1, a qual é a terceira maior cidade do estado de Pernambuco, pertencente a região Nordeste do país. Dos seus 43,55 km² de extensão territorial, $9,73 \mathrm{~km}^{2}$ fazem parte da ZEPEC (Zonas Especiais de Proteção Cultural e Urbanística), com 1,89 $\mathrm{km}^{2}$ da ZEPEC 1 (Sítio histórico) e 7,84 km² do entorno do sítio histórico. A área urbanizada corresponde a quase $98 \%$ do município, tornando-a uma cidade eminentemente urbana (Prefeitura Municipal de Olinda, 2019).

De acordo com Sistema Nacional de Informações sobre Saneamento (SNIS) (2016), Olinda ocupa a posição de $80^{\circ}$ lugar no ranking geral entre as 100 maiores cidades em população no Brasil, em relação à coleta e ao tratamento de esgoto. O índice de coleta de esgoto em Olinda é de 44,40\% dos quais apenas $51,55 \%$ é tratado, fato este que ameaça à saúde pública do município, aumenta o índice de desigualdade social e eleva a poluição de recursos hídricos.

A cidade de Olinda apresenta o relevo formado por planícies e colunas, sendo algumas delas consideravelmente íngremes. Boa parte do território é localizada na bacia do rio Paratibe. A vegetação apresenta uma diversidade de espécies de médio e grande porte que vivem em meio à Mata Atlântica (Prefeitura Municipal de Olinda, 2019). O clima da região é o tropical úmido, caracterizado pela alta temperatura e elevado teor de umidade em que as temperaturas médias anuais giram em torno de $25^{\circ} \mathrm{C}$ e os índices pluviométricos entre 1250 $\mathrm{mm}$ e $2000 \mathrm{~mm}$, onde a amplitude térmica gira em torno de $5^{\circ} \mathrm{C}$ e a densidade demográfica do 
município é de 9.122,11 hab/km² (Prefeitura Municipal de Olinda, 2019).

Figura 1. Localização da área de estudo.

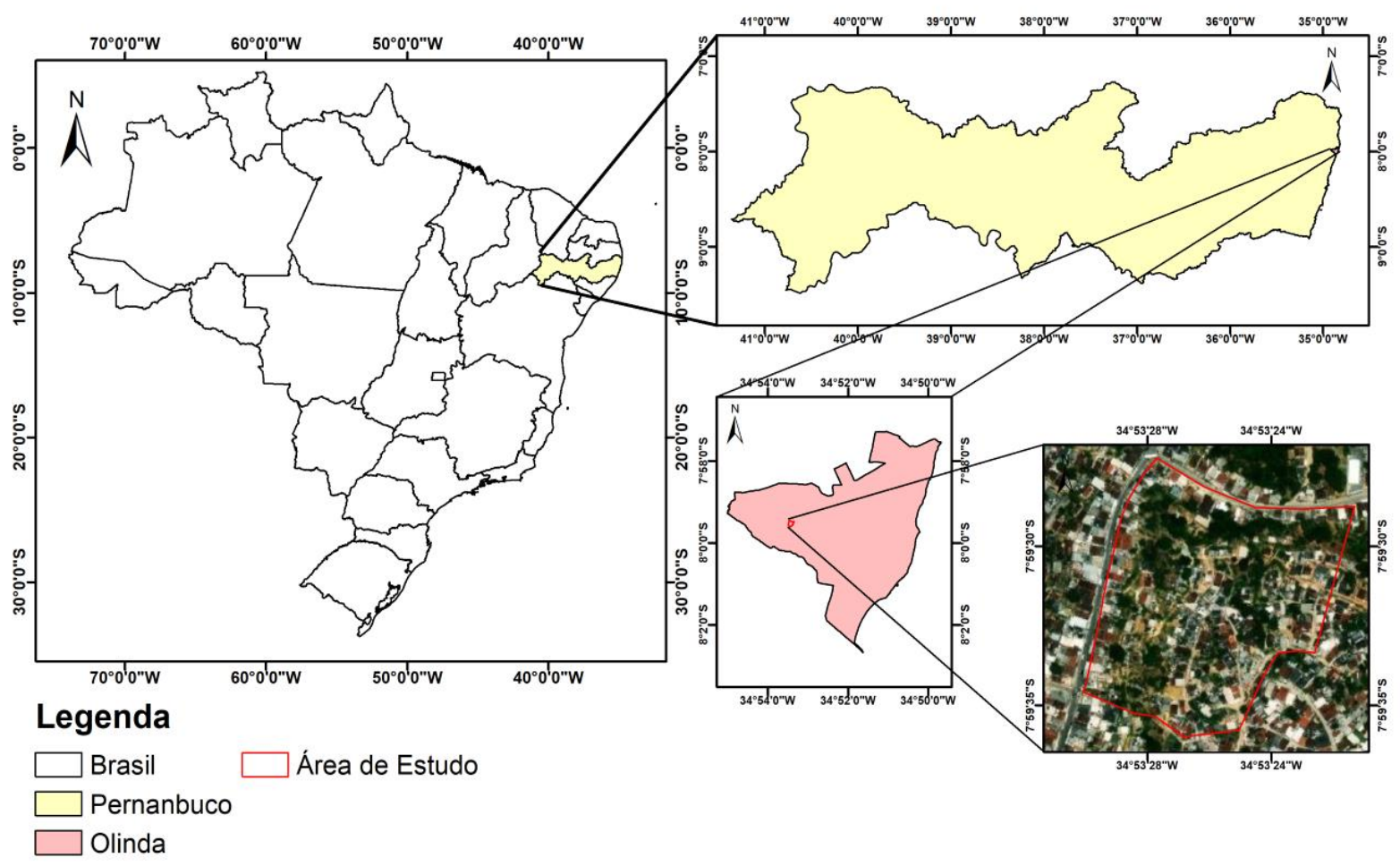

Fonte: Autoras.

O bairro Sapucaia é integrante da $2^{\mathfrak{a}}$ Região Político-Administrativa - RPA 2, possuindo uma área total de $0,87 \mathrm{~km}^{2}$ e população total de 15.024 habitantes. $\mathrm{O}$ bairro em questão é dividido em Sapucaia de dentro e Sapucaia de fora, apresentando como característica comum a presença de comunidades de baixa renda que acabam ocupando áreas de risco de forma desordenada (Prefeitura Municipal de Olinda, 2019).

A localidade, em abril de 2019, sofreu com um deslizamento de barreira que destruiu uma casa, deixando um dos seus moradores feridos, onde a ocupação desordenada aliada com as fortes chuvas acabou por agravar a situação levando a ocorrência do acidente. A defesa civil do município de Olinda, interditou a casa em questão e mais cinco moradias próximas devido ao risco de acidente. Além da intensidade das chuvas, a encosta apresentou uma quantidade de lixo considerável e bananeiras, que contribuíram para o seu deslizamento (Tardin, 2019). Devido a falta de recursos financeiros, boa parte das famílias do bairro são levadas a ocupar de forma desordenada, locais que não oferecem o mínimo de infraestrutura, contribuindo para o aumento do risco de acidentes. 


\subsection{Aspectos socioeconômicos do município}

O município de Olinda possui uma economia intimamente ligada ao turismo cultural, quando observada pela perspectiva de locais próximos ao centro histórico, além de estar essencialmente associada ao comércio local, quando assistida pela ótica de áreas mais afastadas, localizadas nos arredores da cidade, com bairros que acomodam aglomerados subnormais, a exemplo do bairro de Sapucaia.

A região possui um Índice de Desenvolvimento Humano Municipal (IDHM) de 0,735, com apenas $21,7 \%$ da população economicamente ativa, onde a renda média mensal é de 1,7 salários mínimos, referente aos trabalhadores formais, e com 39,7\% da população com rendimento nominal mensal per capita de até metade de um salário mínimo (Instituto Brasileiro de Geografia e Estatística [IBGE], 2010; IBGE, 2017). A união desses aspectos favorece a formação de uma população economicamente precária e ocupante de áreas irregulares.

\subsection{Procedimentos metodológicos}

Inicialmente, foi realizada uma visita ao local em que foi possível observar que a ação antrópica sob as encostas tem sido um fator determinante para a ocorrência de incidentes como esse. A retirada da vegetação original, a ausência de um sistema de esgotamento sanitário adequado, como mostrado na Figura 2(a) e Figura 2(b), os cortes para a construção das casas (Figura 3), que acentuam a inclinação do talude, o despejo inadequado de resíduos aliados com o peso da edificação no terreno, tem se tornado fatores fundamentais para o agravamento da situação, principalmente em períodos chuvosos. Foi observado no local também a presença de vetores transmissores de doenças, como ratos, aumentando o risco à saúde da população. 
Research, Society and Development, v. 9, n. 11, e3499119817, 2020

(CC BY 4.0) | ISSN 2525-3409 | DOI: http://dx.doi.org/10.33448/rsd-v9i11.9817

Figura 2 (a e b). Sistema de esgoto sanitário precário.
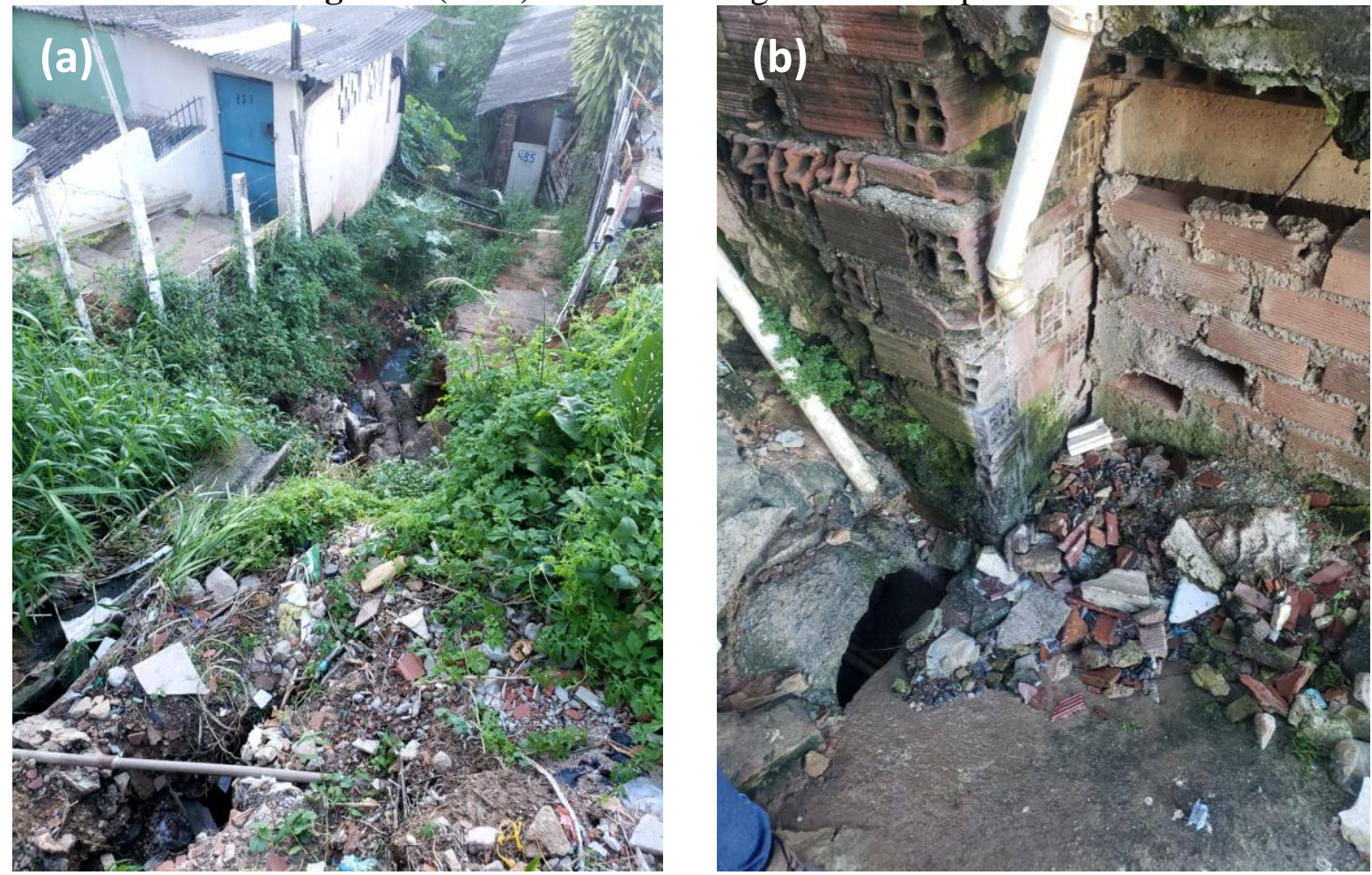

Fonte: Autoras.

Figura 3. Cortes para construções de casas.

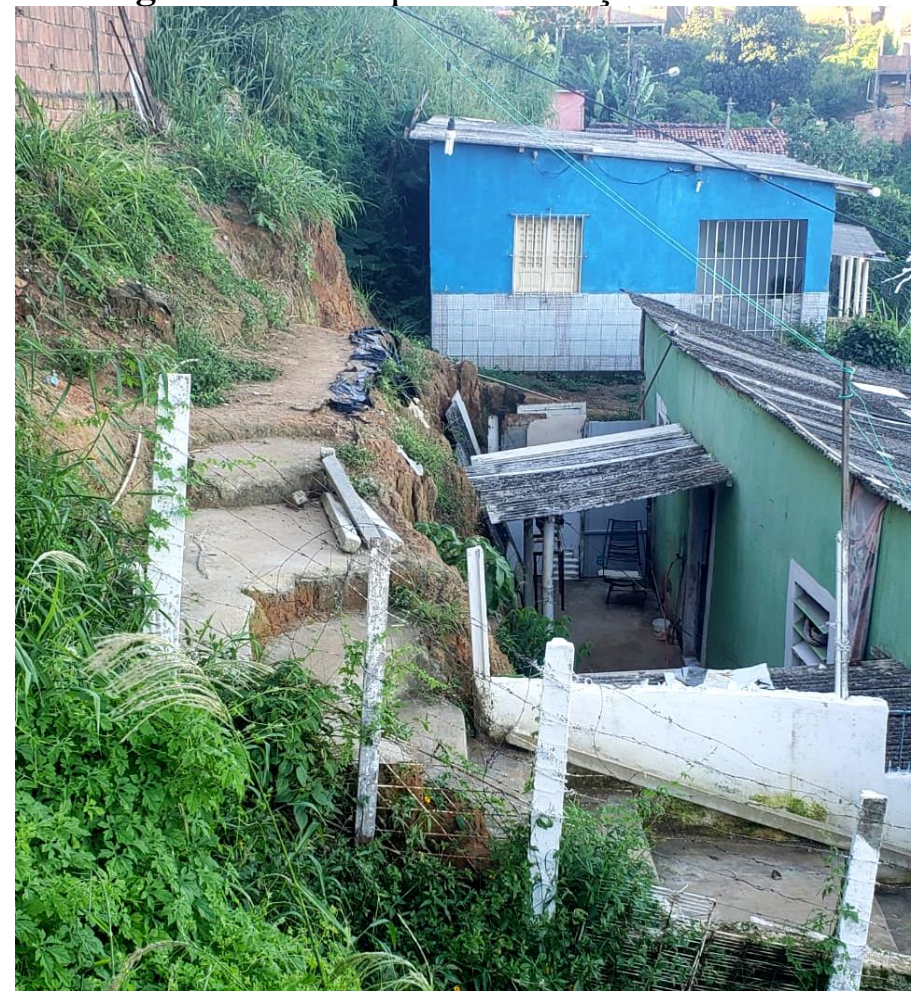

Fonte: Autoras.

Em seguida, foi realizada a elaboração de mapas com as áreas de três tipologias de 
coberturas encontradas na encosta, são elas:

- Área de vegetação: locais com copas de árvores, gramados ou plantas pouco desenvolvidas;

- Área de solo exposto: áreas sem vegetação ou construções;

- Área de mancha urbana: áreas que apresentam moradias, estradas ou superfícies cimentadas as quais contribuem para o escoamento superficial já que reduzem a capacidade de infiltração no solo.

As imagens para a elaboração dos mapas foram obtidas na FIDEM-PE para os anos de 1975 e 1986 e, com o auxílio do Google Earth, foram obtidas as imagens do local para os anos de 2009 e 2018. Através das informações, foi possível realizar a análise quantitativa através do software Qgis encontrando o valor das áreas correspondentes a cada tipologia de cobertura ao longo do tempo, ou seja, os mapas irão oferecer as ferramentas necessárias para que seja realizada a análise temporal da encosta, revelando as características da dinâmica de ocupação do local.

Por fim, a matriz escolhida para a análise do nível de risco foi a de probabilidade/consequência detalhada na Associação Brasileira de Normas Técnicas (ABNT) ISO/IEC 31010, possibilitando a identificação e a avaliação dos indicadores que potencializam a ocorrência de acidentes na encosta (ABNT ISO/IEC 31010, 2012). A matriz probabilidade/consequência é utilizada em inúmeras áreas, para diversos tipos de risco. Elas possibilitam a combinação das classificações qualitativas de consequências e probabilidades a fim de produzir um nível de risco, identificando quais impactos precisam de maior atenção naquele momento (ABNT ISO/IEC 31000, 2018).

A matriz é desenhada com as prováveis consequências em um eixo e a probabilidade de ocorrência no outro. Para compor a matriz, será elaborado um quadro com as ações antrópicas no ambiente natural, como a deposição irregular de lixo, retirada da vegetação original, contaminação do solo, associadas com a probabilidade de ocorrência de alguns fenômenos que afetam o meio ambiente.

A magnitude dos impactos ambientais será avaliada utilizando uma escala que varia de zero até cinco sendo: 0 - nenhum impacto causado; 1 - impacto muito baixo; 2 - impacto de baixo grau; 3 - impacto de médio grau; 4 - impacto de alto grau; e 5 - impacto de altíssimo grau. Para a identificação do nível que os impactos ambientais afetam a encosta, foi separado faixas de percentuais referentes ao total das interações encontradas em relação ao total de 
interações possíveis, atreladas as suas respectivas magnitudes, sendo elas: 0\% a 16,7\% - não afetam; $16,8 \%$ a 33,7\% - afetam em nível muito baixo; 33,8\% a 50,4\% - afetam em nível baixo; $50,5 \%$ a $67,1 \%$ - afetam em nível médio; $67,2 \%$ a $83,8 \%$ - afetam em nível alto e $83,9 \%$ a $100 \%$ - afetam em nível altíssimo. Por fim, foi atribuído um grau de reversibilidade para os indicadores, sinalizando de verde os impactos reversíveis e de vermelho os irreversíveis.

\section{Resultados e Discussão}

\subsection{Análise temporal}

Os mapas obtidos, forneceram informações a respeito da dinâmica de ocupação do local e os dados correspondentes a retirada da vegetação natural. Nas Figuras 4, Figura 5, Figura 6 e Figura 7, referentes aos anos de 1975, 1986, 2009 e 2018, é possível perceber que ocorreu uma redução do tamanho da área de vegetação, e um aumento considerável da área de mancha urbana devido, principalmente, ao surgimento de novas construções na encosta.

Figura 4. Imagem aérea da área de estudo no ano de 1975.

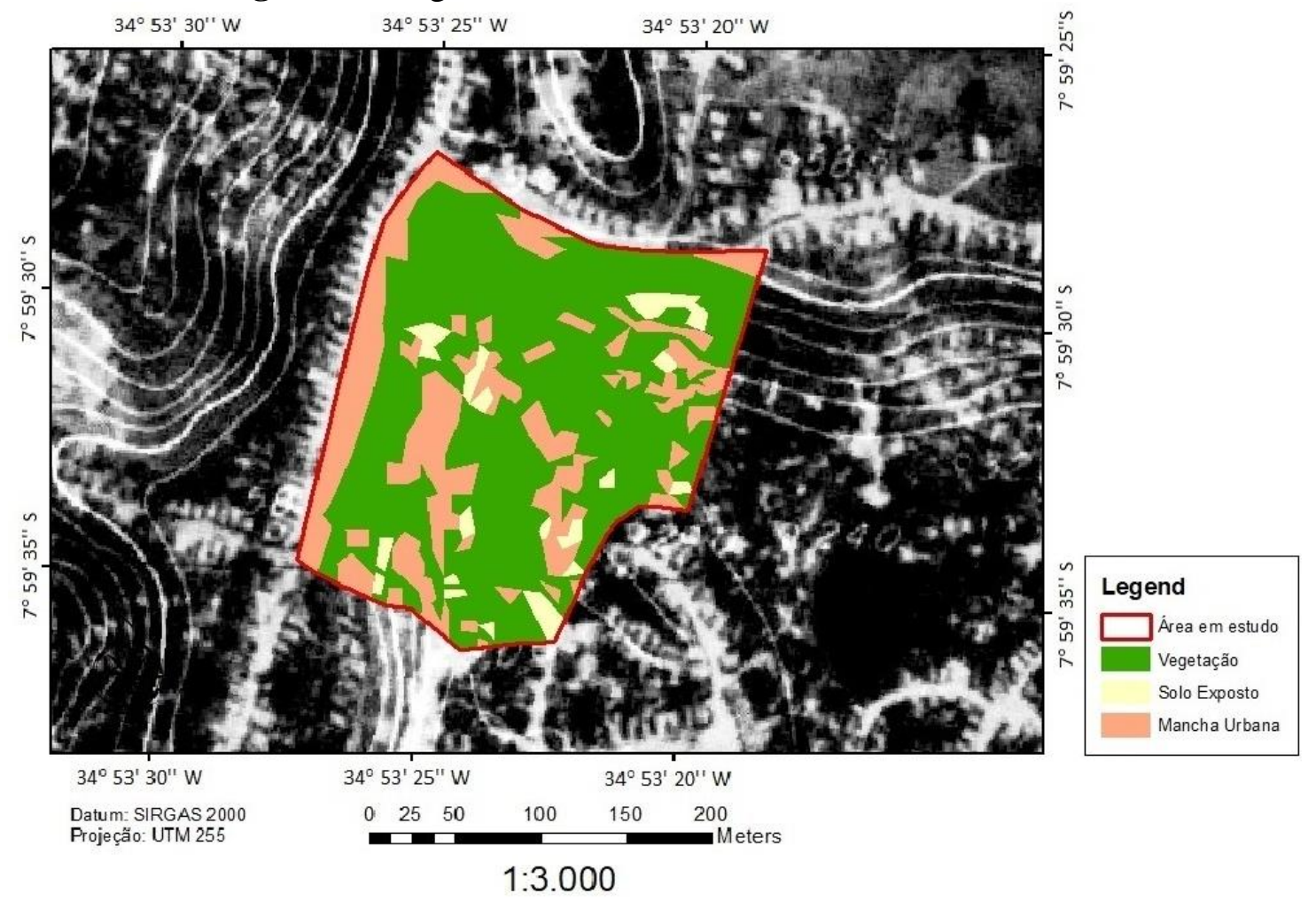

Fonte: Autoras. 
Research, Society and Development, v. 9, n. 11, e3499119817, 2020

(CC BY 4.0) | ISSN 2525-3409 | DOI: http://dx.doi.org/10.33448/rsd-v9i11.9817

Figura 5. Imagem aérea da área de estudo no ano de 1986.

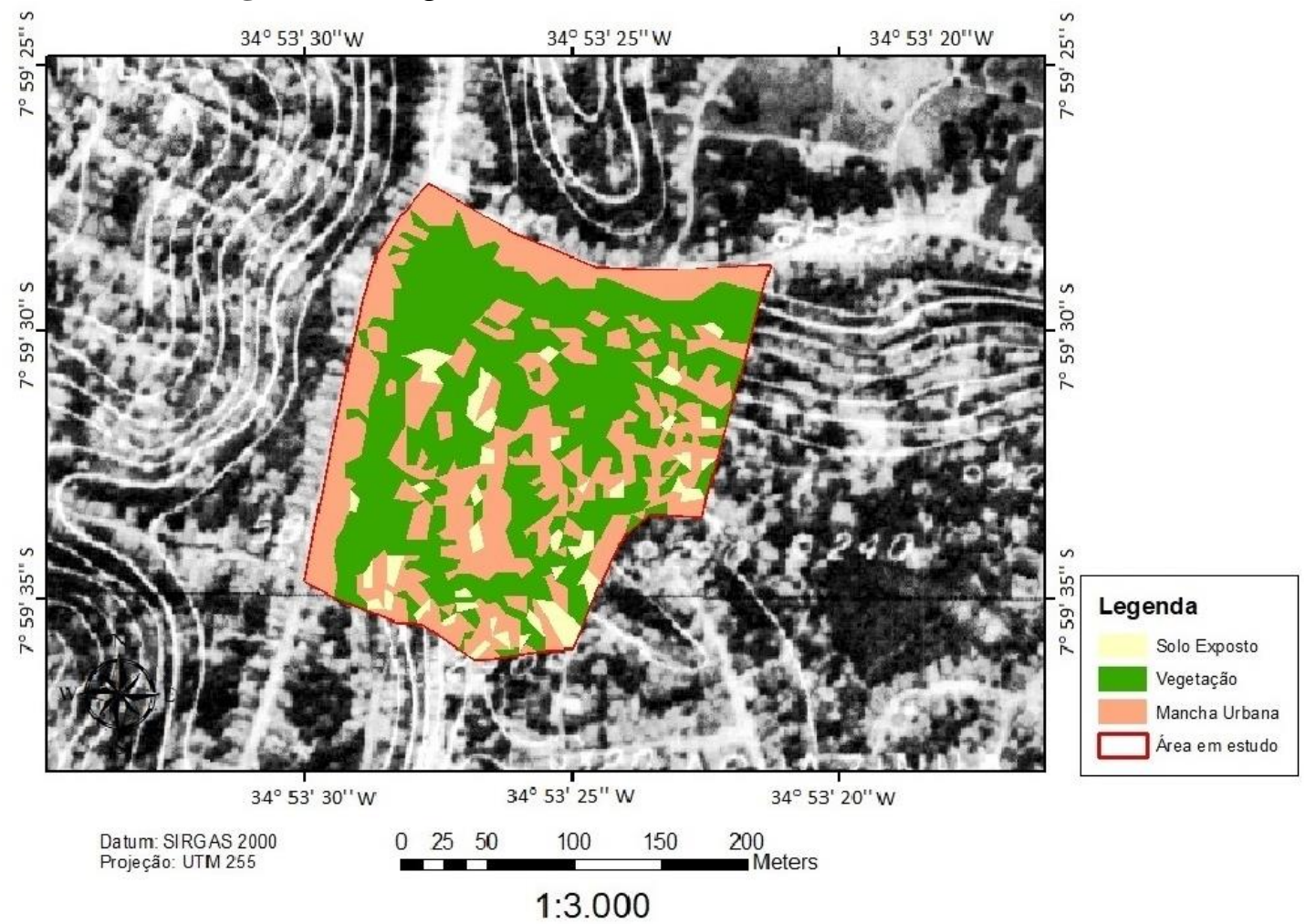

Fonte: Autoras.

Figura 6. Imagem aérea da área de estudo no ano de 2009.

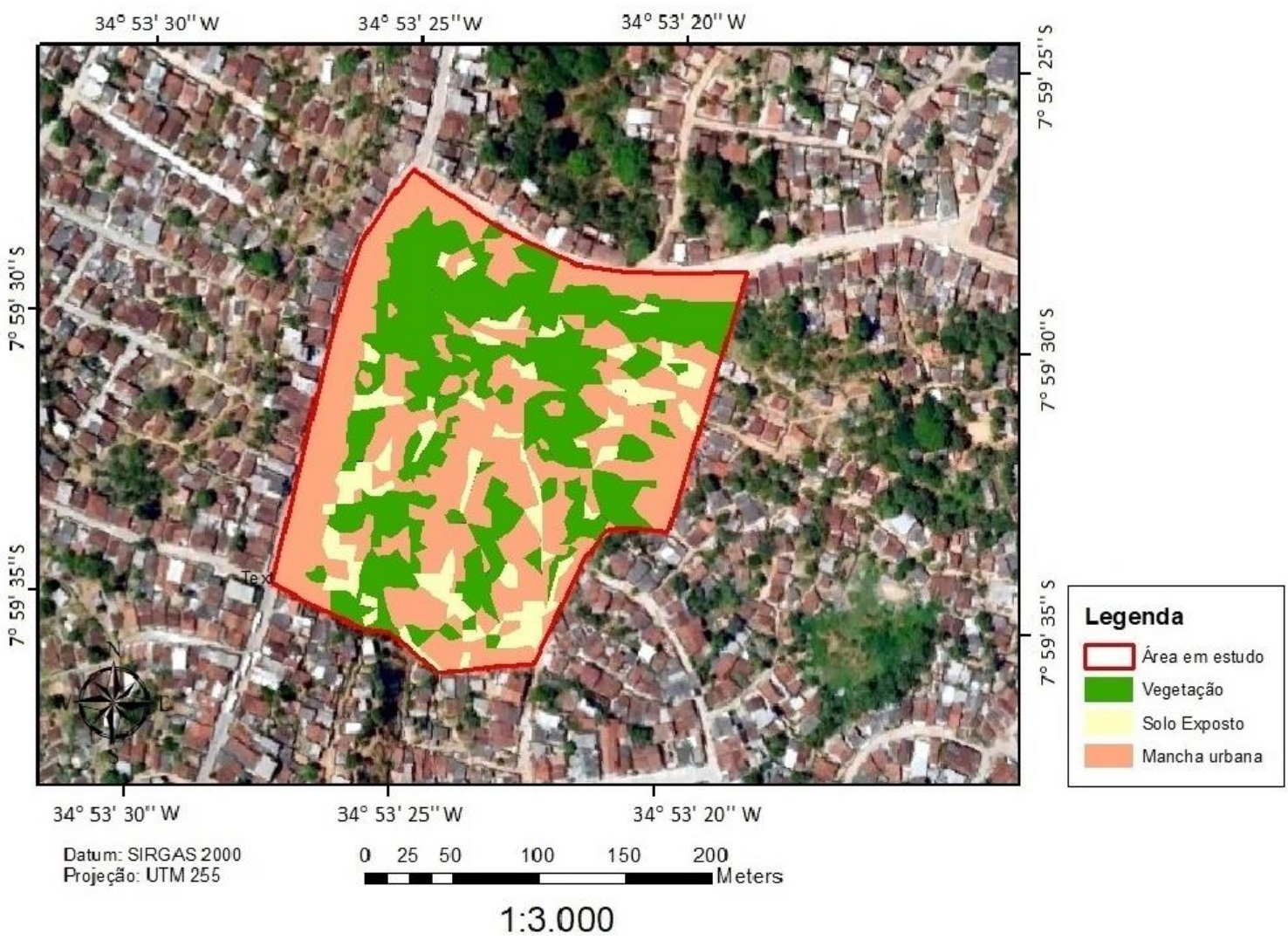

Fonte: Autoras. 
Figura 7. Imagem aérea da área de estudo no ano de 2018.

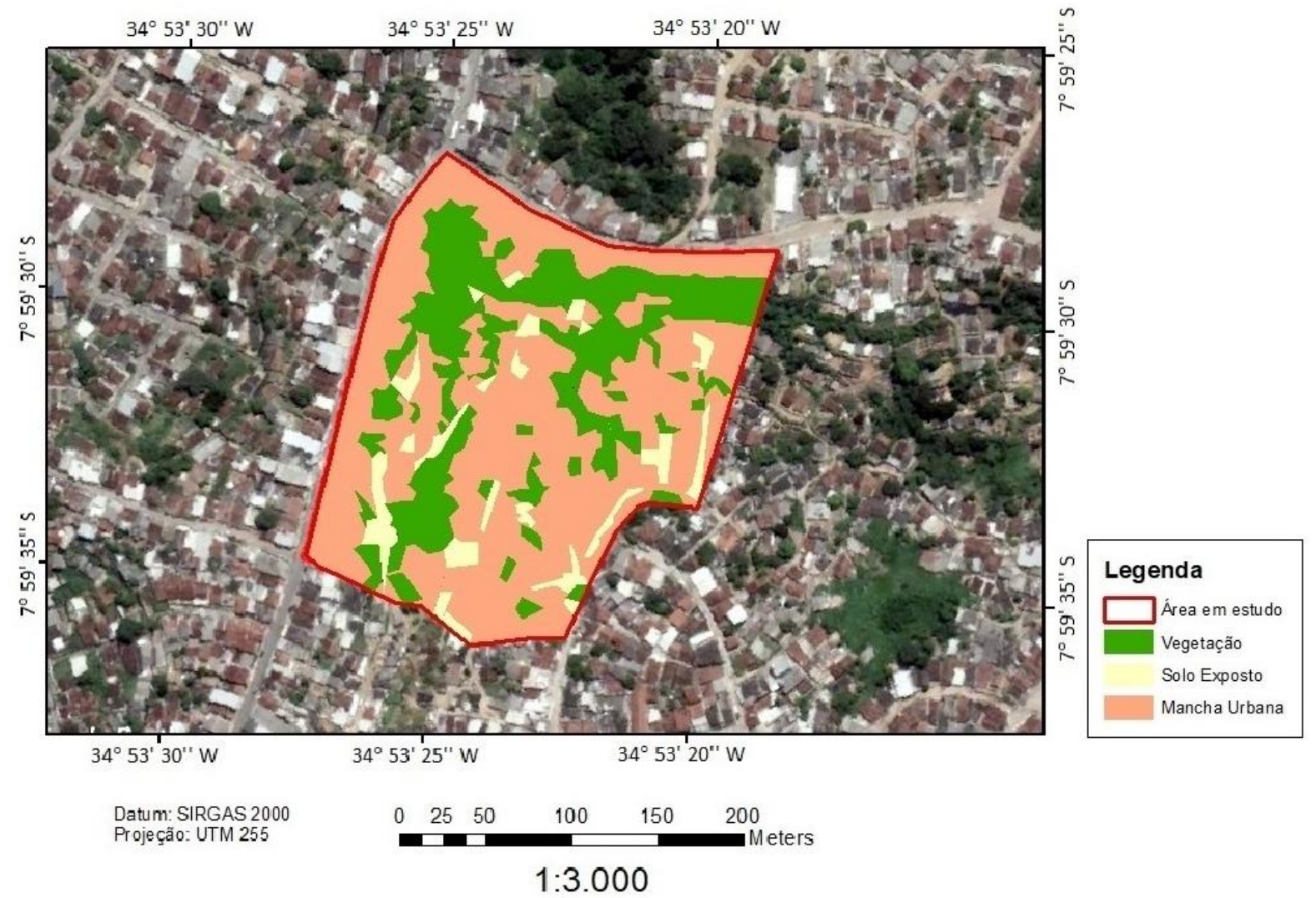

Fonte: Autoras.

A fim de expor as alterações ocorridas referente a todos os elementos analisados (vegetação, solo exposto e mancha urbana), foram elaboradas a Tabela 1 e a Figura 8. Sendo assim, foi possível observar as mudanças ocorridas verificando a taxa de variação e os percentuais relativos as áreas analisadas para os anos de estudo definidos.

Tabela 1. Valores de áreas em $m^{2}$ e taxas de variação para os anos de 1975, 1986, 2009 e 2018 .

\begin{tabular}{c|c|c|c|c|c|c|c|c}
\multirow{2}{*}{ CLASSE } & \multicolumn{4}{|c|}{ Área $\left(\mathbf{m}^{2}\right)$} & \multicolumn{4}{c}{ Taxas de variação $(\%)$} \\
\cline { 2 - 9 } & $\mathbf{1 9 7 5}$ & $\mathbf{1 9 8 6}$ & $\mathbf{2 0 0 9}$ & $\mathbf{2 0 1 8}$ & $\begin{array}{c}\mathbf{1 9 7 5}- \\
\mathbf{1 9 8 6}\end{array}$ & $\begin{array}{c}\mathbf{1 9 8 6 -} \\
\mathbf{2 0 0 9}\end{array}$ & $\begin{array}{c}\mathbf{2 0 0 9 -} \\
\mathbf{2 0 1 8}\end{array}$ & $\begin{array}{c}\mathbf{1 9 7 5 -} \\
\mathbf{2 0 1 8}\end{array}$ \\
\hline Vegetação & 32461,58 & 25549,07 & 19376 & 14480 & 21,29 & 24,16 & 25,30 & 55,40 \\
\hline $\begin{array}{c}\text { Mancha } \\
\text { urbana }\end{array}$ & 13764,48 & 20054,52 & 23800 & 30688 & 45,70 & 18,68 & 28,94 & 122,95 \\
\hline $\begin{array}{c}\text { Solo } \\
\text { exposto }\end{array}$ & 2493,94 & 3116,41 & 5544 & 3552 & 24,96 & 77,90 & 35,93 & 42,42 \\
\hline
\end{tabular}

Fonte: Autoras. 
Research, Society and Development, v. 9, n. 11, e3499119817, 2020

(CC BY 4.0) | ISSN 2525-3409 | DOI: http://dx.doi.org/10.33448/rsd-v9i11.9817

Figura 8. Percentuais das áreas para os anos de 1975, 1986, 2009 e 2018.

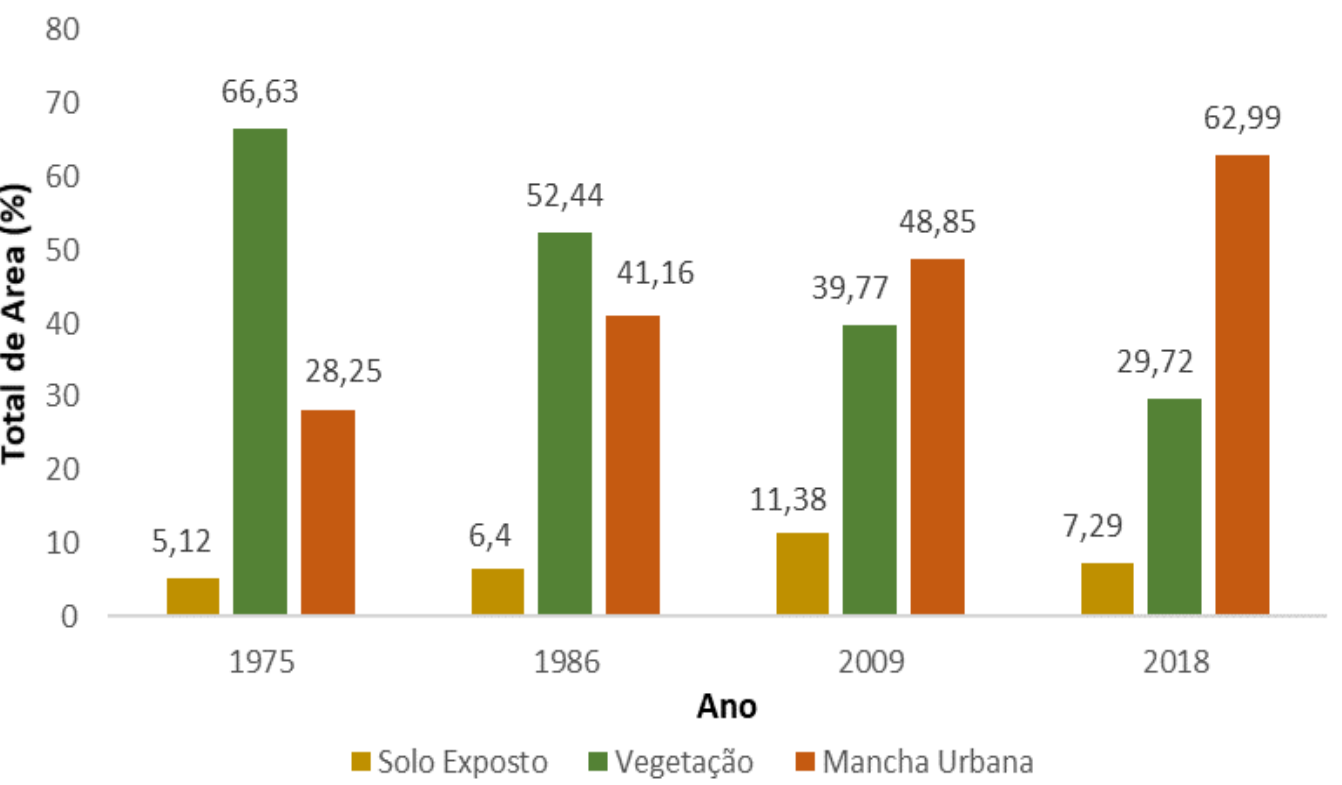

Fonte: Autoras.

A área de vegetação ocupava no ano de 1975 um valor correspondente a 32461, $58 \mathrm{~m}^{2}$ (66,63\%), sendo este o maior valor encontrado para a classe nos anos analisados. Com o passar dos anos, a mesma área passou por um processo de redução em decorrência do aumento da urbanização no local, chegando ao seu menor valor em 2018 com uma área de ocupação de $14480 \mathrm{~m}^{2}(29,72 \%)$. A redução percentual dessa área foi de $55,40 \%$ do ano de 1975 até o ano de 2018. Comportamento semelhante foi encontrado nos trabalhos de Wenzel et al. (2020) e Verde et al. (2020).

A área referente a mancha urbana ocupava um valor de $13764,48 \mathrm{~m}^{2}(28,25 \%)$ no ano de 1975, sendo este o menor valor observado para os anos em estudo. É possível notar que ao longo do tempo, a região referente a macha urbana sofreu um alto crescimento, chegando a um valor de $30688,0 \mathrm{~m}^{2}(62,99 \%)$ no ano de 2018 . O aumento percentual referente a essa área foi de $122,95 \%$, ou seja, o espaço correspondente a mancha urbana sofreu um aumento de mais que o dobro entre os anos de 1975 e 2018, sendo esta a classe que mais sofreu variação na análise temporal. Esse processo pode ser explicado pelo rápido crescimento populacional que acarreta na rápida ocupação de diversos locais, muitas vezes, desordenada, além da intensa migração do campo para a cidade no decorrer dos anos.

A área de solo exposto sofreu um a acréscimo no seu valor para os anos entre 19752009, enquanto que para os anos de 2009-2018, esse valor passou por um decréscimo. Em geral, entre os anos de 1975-2018, a região referente ao solo exposto sofreu um acréscimo de 
42,42\%, sendo esta a menor variação observada diante das classes estudadas. Com a análise temporal, é possível perceber o aumento da ocupação populacional da área de estudo assim como a notória redução da vegetação original ao longo de 44 anos de estudo, sendo estes os principais fatores que influenciam na instabilidade da encosta, aumentando o risco de deslizamentos.

\subsection{Matriz de Probabilidade e Consequência}

A matriz de probabilidade/consequência apresenta 90 quadrículas de interação que foram pontuadas da seguinte forma: 13 quadrículas como impacto de altíssimo grau; 25 quadrículas como impacto de alto grau; 18 quadrículas como impacto de médio grau; 13 quadrículas como impacto de baixo grau; 16 quadrículas como impacto desprezível e por fim, 5 quadrículas consideradas como nenhum impacto, como segue a Tabela 2.

Ao realizar a análise das quadrículas, é verificado que os impactos gerados pela ação antrópica podem atingir magnitude máxima de 50 e mínima de 0 , e para as ações antrópicas a magnitude máxima é de 45 e mínima de 0 . A soma de todas as interações pode atingir a magnitude máxima de 450 pontos.

As interações entre as consequências e a probabilidade resultou numa matriz de magnitude de 261 pontos, ou seja, 58,0\% do total provável, podendo assim concluir que para a área estudada, os impactos ambientais observados afetam em nível mediano. É possível verificar que as ações antrópicas que resultaram num maior impacto são o uso e a ocupação do solo e o esgoto que é lançado diretamente no solo, pontuadas com magnitude de 35 e 32 .

Duas ações apresentaram 29 pontos como magnitude total, são elas: supressão da cobertura vegetal e cortes no terreno para construções. A supressão da cobertura vegetal influenciou com altíssimo grau no processo erosivo e na redução da biodiversidade do local e os cortes no terreno para construções afetaram em altíssimo grau o processo de erosão e a instabilidade do solo. Esses resultados corroboram com os dados obtidos por M. J. P. Santos, T. A. Silva e Lafayette (2019) e E. I. Santos, Alencar, Schramm, J. S. Santos e Nascimento (2020).

Para os impactos gerados, a instabilidade do solo, a redução da biodiversidade e a erosão, são os desastres com maior probabilidade de atingir a área em estudo, com magnitude de 35, 34 e 33 pontos, respectivamente. Do ponto de vista social, a qualidade de vida aparece como a ocorrência com maior probabilidade de afetar a população local devido as ações antrópicas analisadas. 
(CC BY 4.0) | ISSN 2525-3409 | DOI: http://dx.doi.org/10.33448/rsd-v9i11.9817

Com relação ao grau de reversibilidade, apesar da tabela demonstrar que a maioria das interações da matriz possui potencial de reversão, é a partir do diagnóstico dos impactos com característica irreversível que é possível ser avaliado como indicador para riscos de degradação. Nesse sentido, é observado que a maioria das ações antrópicas analisadas possuem potencial de atingir degradação ambiental irreversível.

Tabela 2. Matriz de probabilidade e consequência.

\begin{tabular}{|c|c|c|c|c|c|c|c|c|c|c|}
\hline \multirow[b]{2}{*}{$\begin{array}{c}\text { AÇÃO ANTRÓPICA } \\
\text { QUE PODE GERAR } \\
\text { IMPACTO }\end{array}$} & \multicolumn{10}{|c|}{ IMPACTOS GERADOS } \\
\hline & 蛋 & 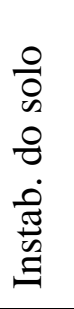 & 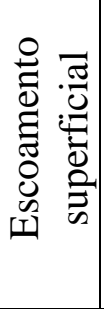 & 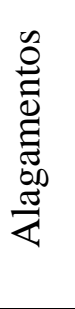 & 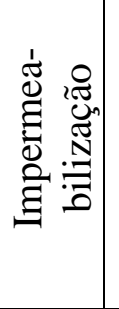 & 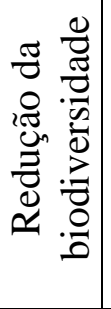 & 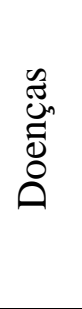 & 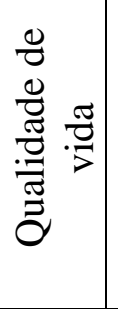 & 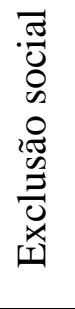 & 离 \\
\hline $\begin{array}{c}\text { Supressão da } \\
\text { cobertura vegetal }\end{array}$ & 5 & 4 & 4 & 4 & 3 & 5 & 1 & 3 & 0 & 29 \\
\hline $\begin{array}{c}\text { Alteração na } \\
\text { consistência do } \\
\text { terreno }\end{array}$ & 5 & 4 & 4 & 4 & 3 & 2 & 1 & 0 & 0 & 23 \\
\hline $\begin{array}{c}\text { Construções em áreas } \\
\text { de encostas }\end{array}$ & 3 & 4 & 2 & 2 & 3 & 3 & 0 & 4 & 4 & 25 \\
\hline $\begin{array}{c}\text { Uso e ocupação do } \\
\text { solo }\end{array}$ & 5 & 5 & 4 & 4 & 4 & 4 & 2 & 4 & 3 & 35 \\
\hline $\begin{array}{c}\text { Esgoto lançado em } \\
\text { fossa séptica }\end{array}$ & 2 & 1 & 2 & 2 & 1 & 1 & 2 & 3 & 1 & 15 \\
\hline $\begin{array}{c}\text { Esgoto lançado } \\
\text { diretamente no solo }\end{array}$ & 4 & 4 & 3 & 2 & 1 & 5 & 5 & 4 & 4 & 32 \\
\hline Tipologia construtiva & 2 & 4 & 3 & 2 & 3 & 1 & 1 & 3 & 3 & 22 \\
\hline $\begin{array}{c}\text { Deposição irregular de } \\
\text { lixo }\end{array}$ & 1 & 3 & 2 & 3 & 1 & 5 & 4 & 5 & 4 & 28 \\
\hline $\begin{array}{c}\text { Contaminação da } \\
\text { água e do solo }\end{array}$ & 1 & 1 & 1 & 1 & 1 & 5 & 4 & 5 & 4 & 23 \\
\hline $\begin{array}{l}\text { Cortes no terreno } \\
\text { para construções }\end{array}$ & 5 & 5 & 4 & 4 & 2 & 3 & 0 & 3 & 3 & 29 \\
\hline TOTAL & 33 & 35 & 29 & 28 & 22 & 34 & 20 & 34 & 26 & 261 \\
\hline
\end{tabular}

Qualificação: 0 - Nenhum impacto; 1 - Impacto desprezível; 2- Impacto de baixo grau; 3 Impacto de médio grau; 4 - Impacto de alto grau; 5 - Impacto de altíssimo grau Reversibilidade: Reversível ou Irreversível

Fonte: Autoras.

Nesse sentido, o plano diretor do município de Olinda/PE tem se mostrado um instrumento precário, uma vez que não fornece o suporte necessário para assegurar a 
população condições dignas de moradia e bem estar, abordando de forma superficial a situação da população que se encontra em áreas de risco.

Os resultados alcançados por Bontempo Filho e Coutinho (2017) também relatam a fragilidade do município de Olinda para lidar com áreas vulneráveis. Ademais, sugerem medidas a serem adotadas pelo município, dentre as quais se destacam: a revisão do Plano Diretor Municipal, com intervenções voltadas para áreas suscetíveis, além da elaboração e aplicação de um plano de ações direcionado à prevenção e mitigação dos riscos.

\section{Considerações Finais}

Foi realizada a identificação e a análise dos impactos socioambientais decorrentes da ação antrópica numa encosta localizada no município de Olinda-PE, no bairro de Sapucaia. Com a análise temporal, é possível perceber que ocorreu uma redução da área de cobertura vegetal no valor de 55,40\% ao longo dos 43 anos analisados (1975-2018), ao passo que a área de mancha urbana cresceu um percentual de 122,95\% em relação ao ano de 1975.

A área de solo exposto sofreu um aumento de 42,42\% em relação ao ano de 1975 , apresentando redução entre os anos de 2009 e 2018 no valor de 35,93\%. A região de solo exposta foi a que apresentou a menor variação percentual ao longo dos anos em estudo. Em 1975, a área de vegetação ocupava um valor de 32461,58 $\mathrm{m}^{2}$ representando 66,63\% da área total de estudo, chegando ao seu menor valor em 2018 com $14480 \mathrm{~m}^{2}$ que representa 29,72\% do local analisado. Em relação a região de mancha urbana, percebe-se que seu menor valor ocorreu no ano de 1975 e foi de $13764,48 \mathrm{~m}^{2}$ que representava $28,25 \%$ da área total em estudo. No ano de 2018, é possível notar o acréscimo considerável dessa classe, passando a ter uma área de $30688 \mathrm{~m}^{2}$ que representa 62,99\% do local de análise.

Dessa forma, a ausência no controle do uso e ocupação do solo, assim como a ausência de uma gestão urbana eficiente, deu origem a esse tipo de evento que contribui para a vulnerabilidade dessas áreas, potencializando a ocorrência de desastres ambientais. Com a realização da matriz de probabilidade e consequência, foi verificado que as ações antrópicas que mais potencializam a ocorrência de impactos na área são: uso e ocupação do solo, esgoto lançado diretamente no solo, supressão da cobertura vegetal, afetando com altíssima intensidade a redução da biodiversidade, e os cortes no terreno para as construções.

Em relação aos impactos com maior probabilidade de atingir a área de estudo, a instabilidade do solo, a redução da biodiversidade e a erosão foram os que apresentaram maior magnitude. Em relação ao aspecto social, a qualidade de vida aparece como a 
ocorrência com maior probabilidade de afetar a população local devido as ações antrópicas pontuadas. A matriz de probabilidade e consequência apresentou 261 pontos, representando $58 \%$ em relação à máxima magnitude possível. Sendo assim, foi aferido que para a área de estudo, os impactos ambientais analisados afetam ou interferem em nível mediano.

A utilização de softwares e métodos de análise de riscos, que permitem uma observação dos impactos ambientais em determinada área, devem ser usados como um instrumento de diagnóstico ambiental com o objetivo de reduzir a degradação no meio natural, fornecendo ferramentas para o planejamento urbano com a redução de desastres ambientais que trazem danos econômicos e à própria vida da população.

\section{Referências}

Abrantes, P., Gomes, E., Rocha, J., \& Teixeira, J. (2018). Uso e ocupação do solo no concelho de Lousada: dinâmicas, padrões e futuro provável. Lucanus, 2, 94-108. Recuperado de https://repositorio-aberto.up.pt/bitstream/10216/117685/2/303685.pdf.

Andrade, E. de L., Calheiros, S. Q. C., \& Conceição, D. N. da (2018). Áreas críticas à ocupação urbana sujeitas a deslizamento de terra na bacia hidrográfica do riacho Reginaldo, Maceió-AL. Revista Contexto Geográfico, 3(5), 1 - 11. Recuperado de file://C:/Users/aless/Desktop/Mestrado/ARTIGO\%20AL\%C3\%89SSIA/Aceite\%20rsd\%20E \%20CORRE\%C3\%87\%C3\%830\%20DO\%20ARTIGO/para\%20excluir.pdf.

Associação Brasileira de Normas Técnicas (ABNT). (2018). NBR ISO/IEC 31000. Gestão de Riscos - Princípios e Diretrizes. Rio de Janeiro.

Associação Brasileira de Normas Técnicas (ABNT). (2012). NBR ISO/IEC 31010. Gestão de Riscos - Técnicas para o Processo de Avaliação de Riscos. Rio de Janeiro.

Barboza, E. N., Bezerra Neto, F. das C., \& Caiana, C. R. A. (2020). Geoprocessamento aplicado na análise dos efeitos da urbanização no campo térmico em Fortaleza, Ceará. Research, Society and Development, 9(7), e57973731, 1-21. DOI: 10.33448/rsd-v9i7.3731.

Bontempo Filho, E. B., \& Coutinho, R. Q. (2017). Análise da vulnerabilidade a desastres naturais no município de Olinda - PE. Estudos Geológicos, 27(1), 61-81. Recuperado de 
file://C:/Users/aless/Desktop/Mestrado/ARTIGO\%20AL\%C3\%89SSIA/Aceite\%20rsd\%20E \%20CORRE\%C3\%87\%C3\%830\%20DO\%20ARTIGO/para\%20excluir.pdf.

Carvalhais, R. M., Moraes, N. A. de, Silva, H. F., \& Bernardes, I. M. M. (2019). Deslizamento de encostas devido a ocupações irregulares. Brazilian Journal of Development, 5(7), 9765-9772. DOI:10.34117/bjdv5n7-150.

Carvalho, R. C de (2019). As migrações e a urbanização no Brasil a partir da década de 1950: um breve histórico e uma reflexão à luz das teorias de migração. Revista Espinhaço, 8(1), 2433. DOI: https://doi.org/10.5281/zenodo.3345139.

Gerui, L., Yalin, Y., Huajun, Y., Sanmang, W., \& Jianping, G. (2017). The influence of land urbanization on landslides: an empirical estimation based on chinese provincial panel data. Science of the Total Emvironment, 595, 681-690. DOI: 10.1016/j.scitotenv.2017.03.258.

Girão, I. R. F., Rabelo, D. R., \& Zanella, M. E. (2018). Análise teórica dos conceitos: Riscos Socioambientais, Vulnerabilidade e Suscetibilidade. Revista de Geociências do Nordeste, 4, 71-83. Recuperado de https://periodicos.ufrn.br/revistadoregne/article/view/13273/9468.

Instituto Brasileiro de Geografia e Estatística (IBGE). (2010). Censo 2010. Recuperado de https://censo2010.ibge.gov.br/noticiascenso.html?view=noticia\&id=3\&idnoticia=1766\&busc $\mathrm{a}=1 \& \mathrm{t}=$ censo-2010-populacao-brasil-190-732-694-pessoas.

Instituto Brasileiro de Geografia e Estatística (IBGE). (2017). Conheça cidades e estados do Brasil. Recuperado de https://cidades.ibge.gov.br/brasil/pe/olinda/panorama.

Lei n. 026, de 2004, alterada pela Lei n. 032, de 2008. Institui o plano diretor do município de Olinda. Recuperado de https://www.olinda.pe.gov.br/wpcontent/uploads/2016/04/revisao_plano_diretor_lei026-2004_revisado_lei-32-2008.pdf.

Leite, G. T. D., Pinheiro, R. Z. G., \& Pamboukian, S. V. D. (2019). Monitoramento de áreas de risco com a utilização de técnicas de geoprocessamento. Revista Mackenzie de Engenharia e Computação, 19(1), 28-47. $\quad$ Recuperado de https://www.mackenzie.br/fileadmin/ARQUIVOS/Public/1- 
Research, Society and Development, v. 9, n. 11, e3499119817, 2020

(CC BY 4.0) | ISSN 2525-3409 | DOI: http://dx.doi.org/10.33448/rsd-v9i11.9817

mackenzie/universidade/laboratorios/labgeo/2019/Trabalhos/MONITORAMENTO_DE_\%C3 \%81REAS_DE_RISCO_COM_A_UTILIZA\%C3\%87\%C3\%83O_DE_T\%C3\%89CNICAS_ DE_GEOPROCESSAMENTO.pdf.

Matos, K. C., Falcão, A. L. S., Lopes, W. G. R., Santiago, D. R., \& Sampaio, I. M. R (2020). Importância dos planos urbanísticos e espaços livres para a sustentabilidade urbana: estudo na Cidade de Teresina, Piauí. Research, Society and Development, 9(10), e859108290, 1-33. DOI: http://dx.doi.org/10.33448/rsd-v9i10.8290.

Mello, P. F. de (2018). Influência da face na estabilidade de taludes em solo grampeado. Dissertação de Mestrado, Universidade Estadual do Rio de Janeiro, Rio de Janeiro, RJ, Brasil. Recuperado de http://www.labbas.eng.uerj.br/pgeciv/nova/files/dissertacoes/163.pdf.

Miranda, H., \& Gomes Júnior, E. (2017). Urbanização reflexa: a emergência de arranjos urbanos intermediários no Brasil pós-1990. Eure, 43(130), 207-234. Recuperado de https://scielo.conicyt.cl/pdf/eure/v43n130/0250-7161-eure-43-130-0207.pdf.

Oliveira, C. G. de, \& Giudice, D. S. (2017). Impactos socioambientais em áreas de ocupação espontânea o exemplo de Vila Canária - Salvador-BA. Revista Tocantinense de Geografia, 6(9), 65-87. Recuperado de file://C:/Users/aless/Desktop/Mestrado/ARTIGO\%20AL\%C3\%89SSIA/Aceite\%20rsd\%20E \%20CORRE\%C3\%87\%C3\%830\%20DO\%20ARTIGO/para\%20excluir.pdf.

Pereira, A. J., \& Dias, J. B. (2020). A urbanização da cidade de Araguaína - TO. Revista Tocantinense de Geografia, 9(17), 134-154. Recuperado de file://C:/Users/aless/Desktop/Mestrado/ARTIGO\%20AL\%C3\%89SSIA/Aceite\%20rsd\%20E \%20CORRE\%C3\%87\%C3\%830\%20DO\%20ARTIGO/para\%20excluir.pdf.

Prefeitura Municipal de Olinda. (2019). A cidade. Recuperado de https://www.olinda.pe.gov.br/a-cidade/olinda-em-dados/.

Santana, J. K. R. de, \& Listo, F. de L. R. (2018). Alterações morfológicas de encostas e deflagração de escorregamentos em áreas densamente urbanizadas: uma análise evolutiva em 
uma sub-bacia do município de Recife (PE). Revista de Geografia, 35(3), 1-19. Recuperado de https://periodicos.ufpe.br/revistas/revistageografia/article/view/235066/29994.

Santos, A. M. S. (2020). Política urbana no Brasil: a difícil regulação de uma urbanização periférica. Geo UERJ, 36, e48434, 1-19. DOI: https://doi.org/10.12957/geouerj.2020.47269.

Santos, E. I. dos, Alencar, M. L. S. de, Schramm, V. B., Santos, J. S. dos, \& Nascimento, M. T. C. C. do (2020). Uso de geotecnologias no estudo da degradação das terras da bacia do rio Sucuru, na Paraíba. Ciência e Natura, 42(57), e.57. DOI:10.5902/2179460X33089.

Santos, E. de O., Falcão, N. A. de M., \& Lima, J. V. A. de (2020). Deslizamento de encostas urbanas: consequências e implicações sociais, ambientais e políticas, em Viçosa/AL, Brasil. Diversitas Journal, 5(3), 1859-1886. DOI: https://doi.org/10.17648/diversitas-journal-v5i31176.

Santos, M. J. P. dos, Silva, T. A. da, \& Lafayette, K. P. V. (2019). Impactos ambientais causados por resíduos sólidos numa encosta no município de Recife-PE. Aguiar, A. C.; Silva, K. A.; El-Deir, S. G. (Org.). Resíduos Sólidos: impactos socioeconômicos e ambientais (8392). Recife: EDUFRPE. Recuperado de https://www.dropbox.com/s/hyonelf145oc6zk/ebook_impacto_\%20socioamb-min.pdf?dl=0.

Sistema Nacional de Informações sobre Saneamento (SNIS). (2016). Série Histórica: Municípios 2016. Recuperado de http://app4.cidades.gov.br/serieHistorica/.

Speth, G., Peres, L. E. da S., Wollmann, L., Domingues, Q. R., \& Ribeiro, B. M. G. (2020). Conflitos do uso de solo em Áreas de Preservação Permanente em Candelária (RS). Ciência e Natura, 42(Special Edition), e13. DOI: 10.5902/2179460X40485.

Tardin, R. (2019). Deslizamento de barreira atinge e destrói casa em Olinda. Olinda: G1. Recuperado de https://g1.globo.com/pe/pernambuco/noticia/2019/04/12/casa-e-atingida-emdeslizamento-de-barreira-em-olinda.ghtml. 
Yu, Y., Yang, X., \& Li, K. (2019). Effects of the terms and characteristics of cadres on environmental pollution: Evidence from 230 cities in China. Journal of environmental management, 232, 179-187. DOI: 10.1016/j.jenvman.2018.11.002.

United Nations Human Settlements Programme. (2016). Urbanization and Development: Emerging Futures. Recuperado de https://unhabitat.org/wp-content/uploads/2014/03/WCR\%20Full-Report-2016.pdf.

Verde, M. R. V., Santana, L. S. G. de, Almeida, P. N. L. de, Reis, R. B., Mello, M. M. C., \& Cavalcante, M. M. (2020). Expansão urbana e redução de áreas verdes em Salvador/BA: o caso do Parque São Bartolomeu. Research, Society and Development, 9(10), e1199106913, 123. DOI: http://dx.doi.org/10.33448/rsd-v9i10.6913.

Wenzel, D. A., Sousa Junior, M. F. de, Uliana, E. M., \& Mendes, M. A. dos S. A. (2020). Dinâmica da cobertura do solo em três bacias hidrográficas da região amazônica do estado de Mato Grosso, Brasil. Research, Society and Development, 9(10), e3919108613, 1-24. DOI: http://dx.doi.org/10.33448/rsd-v9i10.8613.

\section{Porcentagem de contribuição de cada autor no manuscrito}

Aléssia de Albuquerque Pedrosa - 50\%

Suyanne Monteiro de Almeida - 25\%

Kalinny Patrícia Vaz Lafayette - 25\% 